\title{
И.В. Лысак
}

\section{ИДЕНТИЧНОСТЬ: СУЩНОСТЬ ТЕРМИНА И ИСТОРИЯ ЕГО ФОРМИРОВАНИЯ}

\begin{abstract}
Рассматривается история возникновения понятия «идентичность», показана эволюиия термина: от характеристики свойства вещей, позволяющего им сохранять свою специфику при всех изменениях и преобразованиях, до обозначения сложных характеристик иелостности внутреннего мира человека. Обосновывается, что идентичность в ее современном понимании присуща только субъекту - активному, действующему лииу, способному мыслить и осознавать себя.

Ключевые слова: идентичность, идентификация, тождество, самотождественность, самость.
\end{abstract}

В последние годы слово «идентичность» все чаще используется как в научном дискурсе, так и в публицистике. Оно звучит с телеэкрана, встречается в заголовках статей, к месту и не к месту используется в повседневной языковой практике в самых разных словосочетаниях: от вполне академичного - «национальная идентичность» - до абсурдных - «гастрономическая идентичность региона» [1]. Менеджеры всерьез рассуждают об «идентичности бренда» [2], представители модной индустрии дают проводимой ими конференции «громкое» и «модное» название: «Национальная идентичность бренда. Made in Italy и Made in Russia». Название сериала «Dupla Identided» переводят с португальского не как «Раздвоение личности», а «Двойная идентичность». В СМИ постоянно встречаются «странные» фразы, типа: «Папа римский Бенедикт XVI назвал однополые браки попыткой людей манипулировать данной им Богом идентичностью» или «Пока ученые лишь приблизительно понимают идентичность Ульяновской области» [3, 4]. Такая широкая практика словоупотребления побуждает обратиться как к анализу сущности самого термина «идентичность», так и к истории его формирования, во многом проливающей свет на существующую неоднозначность трактовок.

Как известно, понятие «идентичность» (англ. identity) происходит от латинского корня «іdem», означающего «то же самое». В этом первичном смысле оно использовалось мыслителями Древности и Средневековья, выяснявшими, что делает вещь именно этой вещью, отличной от других. Идентичность обозначала свойство вещей оставаться теми же самыми, сохранять свою сущность, свою специфику при всех изменениях и преобразованиях. В русских переводах понятие «идентичность», как правило, заменялось словом «тождество» или «тождественность».

Постепенно термин «идентичность» начинает использоваться для характеристики уже не бытия вещей, неодушевленных предметов, а для обозначения единичного человеческого существования, бытия личности, ее «самости», приобретая значение «самотождественности» или «личного тождества». Считается, что ранее других проблему «личного тождества» (англ. personal 
identity) начинает осмысливать в XVII в. английский педагог и философ Дж. Локк. В работе «Опыт о человеческом разумении» («Concerning Human Understanding») Дж. Локка есть глава «О тождестве и различии» («Of Identity and Diversity»), в которой он анализирует и переосмысливает существующие концепции тождества (англ. identity). Английский мыслитель значительно расширил прежние представления об идентичности или тождестве, разделив идентичность предметов, заключающуюся в их полной тождественности друг другу (например, так тождественны два экземпляра одной и той же книги), и идентичность личности, заключающуюся в ее способности приписывать себе свои прежние состояния. Дж. Локк полагал, что залогом существования личности является непрерывность сознания и наличие памяти. Он опровергал господствовавшее в то время утверждение, что тождественность личности может быть задана душой, ведь душа бессмертна, и если признать ее в качестве критерия, это открыло бы возможность для перемещения душ. Тогда, указывает Дж. Локк, люди, жившие в различное время, были бы одной и той же личностью, что абсурдно. Не душа, а сознание обеспечивает тождество личности. Сама же личность определяется Дж. Локком как «разумное мыслящее существо, которое имеет разум и рефлексию и может рассматривать себя как себя, как то же самое мыслящее существо, в разное время и в различных местах благодаря тому сознанию, которое неотделимо от мышления, < ..> благодаря этому каждый бывает “самим собой”, тем, что он называет Я (self), причем в этом случае не принимается во внимание, продолжается ли то же самое Я в той же самой или различных субстанциях» [5. C. 387]. Дж. Локк показывает, что с течением времени человек меняется, однако изменение физического облика человека, его «материальной субстанции» не приводит к утрате идентичности (тождественности). Этот тезис он поясняет на примере взросления, а затем старения человека: юноша и старец считаются единой личностью. Это единство обеспечивается способностью человека помнить о совершенных им в прошлом действиях и осознавать, что это были именно его действия. Таким образом, идентичность личности, по Дж. Локку, отличается от тождественности неодушевленных предметов, она обусловлена наличием у человека сознания и памяти и не исключает изменчивости.

Для обозначения того неуловимого, что создает основу личности и обеспечивает ее единство, в XIX - начале XX в. исследователи использовали понятие «Self», в русских переводах - «самость». Известные социологи Г. Зиммель, Дж. Мид, Ч. Кули показали, что «самость» формируется у человека только в контексте социального взаимодействия. Так, немецкий ученый Г. Зиммель полагал, что человек обретает «самость» в ходе самоприписывания к определенным социальным группам, рассматриваемым как «свои», и самопротивопоставления иным общностям, осознаваемым в качестве «чужих» [6]. В результате указанных процессов индивид, с одной стороны, осознает свою принадлежность к определенному социальному окружению, общность с ним, с другой стороны, выделяет себя из этого окружения, понимая свою особость, «самость».

Американский философ и социолог Дж. Мид обосновывал, что формирование «самости» происходит в ходе становления у человека образа 
«обобщенного Другого» [7]. «Самость»- это своего рода умение видеть себя глазами других людей. В структуре «самости» Дж. Мид выделял две составляющих, которые обычно приводят без перевода: «Ме» (англ. те - «меня») и «I» (англ. $I$ - «я)». Мe - это совокупность норм, ценностей, установок, которыми руководствуется человек, и которые формируются у него в процессе социальных взаимодействий и являются результатом социальных ожиданий. Это осознаваемые, но некритически усвоенные правила поведения в том или ином сообществе, это то, как индивиды видят себя глазами других, социальная сторона «самости». I представляет собой специфическую, индивидуальную реакцию человека на установки общности, это проявление импульсивности, спонтанности индивида, эмоционально окрашенный отклик на социальное окружение. I отражает индивидуальность и своеобразие человека. В свою очередь, Self выступает как единство Me и I, являющихся двумя половинками одного целого, что может быть выражено формулой Self $=M e+I$. То есть «самость», по Дж. Миду, включает как социокультурный, так и индивидуальный компоненты, находящиеся в неразрывном единстве.

Развивая представления о «самости», американский социолог и социальный психолог Ч. Кули в своих работах предложил концепцию так называемой зеркальной самости (англ. looking-glass self), в русскоязычных переводах обычно обозначаемую как «теория зеркального Я». Он пытался показать неразрывную связь общества и личности, показывая, что общество формирует личности, а личности, в свою очередь, конструируют общество. Теория «зеркальной самости» строится на трех базовых положениях: во-первых, в процессе взаимодействия люди способны представлять, как они воспринимаются другими людьми, во-вторых, люди могут прогнозировать ответные реакции других, в-третьих, представление человека о самом себе зависит от того, каким ему видится представление о нем других людей. «Самость» человека, его восприятие самого себе является своего рода зеркальным отражением реакций на него окружающих. Ч. Кули пишет: «Социальную самость такого рода можно назвать отраженной, или зеркальной, самостью... Мы видим наше лицо, фигуру и одежду в зеркале, интересуемся ими, поскольку все это наше, бываем довольны ими или нет в соответствии с тем, какими мы хотели бы их видеть, точно так же в воображении воспринимаем в сознании другого некоторую мысль о нашем облике, манерах, намерениях, делах, характере, друзьях и т. д., и это самым различным образом на нас воздействует» [8]. В основе «социальной самости», по Ч. Кули, лежит врожденная конкуренция с другими. Именно в условиях конкурентного взаимодействия с другими человек понимает, чем он отличается от других, выявляет свои характерные особенности и свои конкурентные преимущества.

Хотя указанные авторы не использовали само понятие «идентичность», выдвинутые ими идеи были использованы в XX в. исследователями, изучающими ее сущность. Сам же термин «идентичность» начинает входить в социологию с 1960-х гг. благодаря работам американских ученых Э. Гоффмана и П. Бергера. Именно Э. Гоффман в книге «Стигма: Заметки об управлении испорченной идентичностью» («Stigma: Notes on the Management of Spoiled Identity»), изданной в 1963 г. в Нью-Йорке, вместо понятия «самость» стал использовать понятие «идентичность» [9]. В том же году 
П. Бергер пишет об идентичности в контексте ролевой теории в своей книге «Приглашение в социологию: гуманистическая перспектива» («Invitation to Sociology: A Humanistic Perspective») [10].

Параллельно с социологами термины «идентичность» и «идентификация» начинают использовать психологи и психиатры. Так, о «перцептивной идентичности» писал основатель психоанализа австрийский психиатр 3. Фрейд. Он определял идентификацию, с одной стороны, как бессознательную связь ребенка с родителями, с другой - как «важный механизм взаимодействия между личностью и социальной группой» [11]. Немецкий психиатр К. Ясперс в защищенной им в 1913 г. докторской диссертации «Общая психопатология» называл идентичность одним из четырех формальных признаков сознания «Я». Идентичность, по его мнению, это осознание того, что я остаюсь тем, кем был всегда, и все происходящие в моей жизни события происходят именно со мной и ни с кем другим. Свидетельством нарушения идентичности, по К. Ясперсу, являются утверждения больных шизофренией о том, что происходившее с ними до начала психоза на самом деле было не с ними, а с кем-то другим [12]. В психиатрии утвердился и особый диагноз: «кризис идентичности», свидетельствующий об утрате психически больными людьми представлений о самих себе и о событиях своей жизни.

По-настоящему популярным термин «идентичность» стал после выхода в свет в 1968 г. книги американского психолога Э. Эриксона «Идентичность: юность и кризис» («Identity: Youth and Crisis») [13]. В этой работе Э. Эриксон рассматривает идентичность как внутреннюю непрерывность и тождественность личности, формирующуюся в процессе развития и выполняющую адаптивные функции. Исследуя проблему, Э. Эриксон выделил три уровня идентичности: индивидный, персональный и социальный. На индивидном уровне идентичность рассматривалась им как результат формирования у человека представления о себе как о некоторой относительно неизменной данности, определенного физического облика, темперамента, задатков, с определенным прошлым и осознаваемым будущим. Персональный уровень идентичности, согласно Э. Эриксону, представляет собой ощущение человеком собственной неповторимости, уникальности своего жизненного опыта. На социальном уровне идентичность определяется исследователем как тот личностный конструкт, который отражает внутреннюю солидарность человека с идеалами и стандартами определенных социальных групп.

В своем исследовании Э. Эриксон показал, что идентичность начинает формироваться у ребенка с первых дней жизни под влиянием его взаимодействия с окружающими. Постепенно у индивида формируется представление о непрерывности и устойчивости своего «Я» в меняющихся ситуациях. Развитие идентичности продолжается на протяжении всей жизни человека по мере того, как расширяется круг значимых для него лиц. Э. Эриксон выделил восемь стадий психосоциального развития личности. Первая стадия связана с выделением ребенком себя из окружения в физическом и социокультурном отношениях. Затем идут две фазы детства, характеризующиеся приобретением опыта индивидуальных успехов и неудач во взаимоотношениях с другими. Далее следуют стадии отрочества и юности, в ходе которых 
формируется «Я-идентичность» и происходит осознание своих отличий от других. За ними идут три стадии взрослости - ранняя, характеризующаяся социокультурным самоопределением, средняя, с присущим ей самостоятельным социокультурным статусом, и поздняя, предполагающая, в зависимости от разрешения «кризиса среднего возраста», либо дальнейшее развитие, либо постепенное угасание процесса личностной самореализации. При переходе от одной стадии жизненного цикла к другой человек испытывает некоторую неопределенность, переживает кризис, который нужно преодолеть, перейдя к следующему стабильному состоянию. Этот процесс не является патологическим, наоборот, он свидетельствует о становлении зрелой личности.

Концепция идентичности Э. Эриксона получила научное признание и способствовала значительной распространенности самого термина. В работах практически всех психологов и психиатров, изучавших идентичность в дальнейшем, присутствуют ссылки на работы Э. Эриксона. Под влиянием его концепции в психологических теориях идентичность связывается в первую очередь со способностью личности оставаться той же самой, претерпевая постоянные изменения.

С начала 1980-х гг. термин «идентичность» начинает активно использоваться в работах, затрагивающих проблемы расовых, национальных и этнических различий. Ученые обращаются к изучению национальной и культурной идентичности, предполагающей наличие самотождественности у нации или народности, позволяющей им определить свое место в мире. Национальная идентичность формируется как осознание сходства в мировоззрении, ценностях, традициях и образе жизни определенной общности, что предполагает четкое разграничение «своего» и «чужого». Использование термина «идентичность» в исследованиях политологов привело к его еще большей распространенности и использованию в многообразных, порой причудливых сочетаниях, о которых говорилось в начале статьи. Такому многообразию трактовок при неопределенности содержания способствует двусмысленность самого термина, подмеченная Дж. Локком и подробно проанализированная уже в XX в. французским философом П. Рикёром (фр. Paul Ricœur, 1913-2005).

Выделенные Дж. Локком два вида идентичности П. Рикёр назвал «idemидентичностью» (идентичностью тождества) и «іpse-идентичностью» (идентичностью «самости»). «Idem-идентичностью» обладают предметы, полностью тождественные друг другу, как два автомобиля одной и той же марки, сошедшие с одного конвейера (в переводе с латыни «idem»- «то же самое»). «Ipse-идентичность» присуща только личности, осознающей саму себя («ipse» в переводе с латыни означает «сам»).

Однако два указанных латинских корня «idem» и «ipse», заложенные в термине идентичность, накладываются друг на друга, привнося, два, казалось бы, несовместимых смысловых значения: устойчивость и постоянство, с одной стороны, и изменчивость - с другой. В работе «Повествовательная идентичность» П. Рикёр пишет: «Согласно первому из них “idem”, “идентичный” - это синоним “в высшей степени сходного”, “аналогичного”. “Тот же самый” [“même”], или “один и тот же”, заключает в себе некую форму 
неизменности во времени. Их противоположностью являются слова “различный”, “изменяющийся”. Во втором значении, в смысле “ipse” термин “идентичный” связан с понятием “самости" [“ipsete”], “себя самого”. Индивид тождествен самому себе. Противоположностью здесь могут служить слова “другой”, “иной”. Это второе значение заключает в себе лишь определение непрерывности, устойчивости, постоянства во времени...» [14. С. 19]. Эту противоречивость, по мнению П. Рикёра, позволяет преодолеть выдвинутая им концепция «повествовательной идентичности». Суть ее заключается в том, что идентичность не дана человеку непосредственно, как некий внутренний опыт. Она формируется лишь посредством повествовательной деятельности, в ходе рассказа, повествования о ней. Предельно упрощенно суть концепции П. Рикёра можно выразить следующим образом: только рассказывая о себе, о своих особенностях и отличиях от других, о принадлежности к тем или иным группам, о своих склонностях и талантах, о своей уникальности, своем прошлом и будущем, человек формирует собственную идентичность. Этот рассказ совсем не обязательно буквально ведется перед широкой или не очень широкой аудиторией. Более того, это может быть глубоко личностный внутренний диалог с самим собой, но он обязательно должен иметь речевое выражение. К идентичности человек может прийти только посредством повествовательной деятельности.

Итак, термин «идентичность» прошел длительную эволюцию: от буквального значения тождества вещи самой себе, которая может быть выражена формулой $\mathrm{A}=\mathrm{A}$, до сложных характеристик целостности внутреннего мира человека. В настоящее время понятие «идентичность» используется в следующих основных значениях: постоянство во времени, самобытность, «самость» как подлинность индивида, психофизиологическая целостность, психологическая определенность, непрерывность жизненного опыта, степень соответствия социальным ожиданиям, принадлежность к той или иной общности. Сложность однозначного определения идентичности объясняется нерешенностью важного вопроса о том, кто или что является ее носителем. Правомерно ли говорить об идентичности применительно к неодушевленным предметам, можно ли всерьез рассуждать об идентичности вещей, будь то конкретная вещь или бренд - торговая марка, имеющая определенный статус и сформированное отношение потребителей. В подавляющем большинстве работ философов, психологов, психиатров, социологов и политологов идентичность рассматривается только как характеристика субъекта, т.е. того, кто является источником свободной активности. Спорят исследователи и о том, обладает ли идентичностью социальная общность, или это понятие применимо лишь к индивиду, ощущающему и осознающему в том числе и свою групповую принадлежность.

По-разному определяется в науке соотношение понятий «идентичность» и «идентификация». Одни исследователи полагают, что идентификация представляет собой процесс или механизм, способствующий формированию идентичности, а идентичность является результатом этого процесса. Другие считают, что сама идентичность носит процессуальный 
характер. Например, российский философ М.В. Заковоротная пишет: «Идентичность можно определить как процесс становления человека на основе выбора и формирования жизненной модели в социальном взаимодействии во имя исторической самореализации» [15. С. 49]. Действительно, идентичность не является раз и навсегда данной, она динамична и требует постоянных усилий по формированию.

Таким образом, первоначально понятие «идентичность» использовалось в рассуждениях философов о природе вещей, их сущности, однако начиная с Нового времени указанный термин стал применяться для характеристики ощущения личностью самотождественности и непрерывности своего существования во времени и пространстве. Под идентичностью понимается также некая устойчивость индивидуальных, социокультурных, национальных или цивилизационных параметров, позволяющих ответить на вопросы: «Кто я?» или «Кто мы?». То есть в настоящее время в науке доминирует представление, что идентичность присуща только субъекту - активному, действующему лицу, способному мыслить и осознавать себя. В таком случае говорить об идентичности можно лишь применительно к человеку или группе лиц, способных осознавать себя и отличать себя от других. Применительно к неодушевленным предметам, будь то «бренд» или «область», употреблять термин «идентичность» не следует. Можно говорить лишь об их идентификации людьми, т. е. об установлении думающими существами их специфичности и принадлежности к определенному виду, классу, группе.

\section{Лuтература}

1. Сильчева Л.В., Бальнин К.А. Гастрономическая идентичность региона. Сущность и практическое значение // Естественные и математические науки в современном мире: Сборник статей по материалам XXXII международной научно-практической конкуренции. № 7 (31). Новосибирск: СибАК, 2015. С. 86-92.

2. Домнин В.Н. Идентичность бренда - ключевое понятие «бренд-менеджмента» // Брендменеджмент. 2009. № 3. С. 130-144.

3. Новиков B. Отдайте ему его идентичность. [Электронный ресурс]: Свободная пресса // URL: http://svpressa.ru/society/article/62627/ (дата обращения: 02.07.2016).

4. Пензин Е. И об идентичности [Электронный ресурс]: Симбирский курьер // URL: http://sim-k.ru/2012/12/20/i-ob-identichnosti/ (дата обращения: 02.07.2016).

5. Локк Дж. Опыт о человеческом разумении // Локк Дж. Соч.: в 3 т. М.: Мысль, 1985. T. 1. C. $78-582$.

6. Simmel G. Group Expansion and the Development of Individuality // Classical Sociological Theory. Blackwell Publishing, 2006. P. 251-293.

7. Mead G.The I and the Me // Mead G. Mind, Self and Society. Chicago, 1934. P. 152-164.

8. Кули Ч. Социальная самость // Американская социологическая мысль / под ред. В.И. Добренькова. М.: Изд-во МГУ, 1994. С. 320-321.

9. Goffman E. Stigma: Notes on the Management of Spoiled Identity. New York: Prentice-Hall, 1963. $147 \mathrm{p}$.

10. Бергер П. Приглашение в социологию: гуманистическая перспектива. М.: Аспект Пресс, 1996. 168 c.

11. Фрейд 3. Массовая психология и анализ человеческого «Я» // Я и Оно: Хрестоматия по истории психологии / под ред. П.Я. Гальперина, А.Н. Ждан. М.: Изд-во МГУ, 1980. С. 170-192.

12. Ясперс К. Общая психопатология. М.: Практика, 1997. 1053 с.

13. Эриксон Э. Идентичность: юность и кризис. М.: Флинта, 2006. 342 с.

14. Рикёр П. Повествовательная идентичность // Рикёр П. Герменевтика. Этика. Политика: Московские лекции и интервью. М.: АО «КАМІ», 1995. С. 19-37. 
15. Заковоротная М.В. Идентичность человека: Социально-философские аспекты. Ростов н/Д: Изд-во СКНЦ ВШ, 1999. 200 с.

Lysak Irina V. Southern Federal University (Rostov-on-Don, Russian Federation)

E-mail: ivlysak@sfedu.ru

DOI: $10.17223 / 1998863 \mathrm{X} / 38 / 13$

Identity: the essence of the term and the history of its formation

Key words: identity, identification, self-identity, self

The term «identity» has gone through a long-term evolution: from the literal meaning of an object's equivalence to itself, to complex characteristics concerning the integrity of a human inner world. Originally, the notion of identity was used in philosophical reflections about the nature of things; however, starting from the early modern age, this term has been applied to characterize a person's sense of sameness and of continuity of their existence through time and space, which is based on the continuity of consciousness and ability to remember. In the 19th and early 20th centuries, they used the concept of «Self» for unity of personality, which may be formed only in a context of social interaction. The basic formation mechanism for «Self» was considered to be a person's self-categorizing as a part of social groups, viewed as «friendlies» and self-opposing to other communities, recognized as «foreigners». As a result of these processes, a person recognizes, on one hand, his affiliation and alliance with a certain social environment and, on the other hand, detaches himself from this environment through awareness of his peculiarity, his selfness. Nowadays, the concept of «identity» is used in the following basic meanings: constancy in time, uniqueness, «selfness» as a personal authenticity, psychophysiological integrity, psychological determinacy, continuity of life experience, degree of conformity to social expectations, and affiliation with a certain community. Along with personal identity there is a notion of «national identity», involving national or ethnic sameness, which allows a nation or ethnicity to determine their place in the world. The article suggests to interpret the concept of identity as a certain fixed combination of individual, sociocultural, national and civil parameters that answer the questions: «Who am I?» or «Who are we?». We can speak of identity only in relation to subjects - a person or a group of persons able to recognize themselves and separate themselves from others. We should not apply this term to inanimate objects. We can speak only of their identification by people, that is, of the determination by intellectual beings of their specificity and affiliation with a certain type, class and group.

\section{References}

1. Silcheva, L.V. \& Balynin, K.A. (2015) Gastronomicheskaya identichnost' regiona. Sushchnost' i prakticheskoe znachenie [Gastronomic identity of the region. Essence and practical significance]. Estestvennye i matematicheskie nauki v sovremennom mire. 7(31). pp. 86-92.

2. Domnin, V.N. (2009) Identichnost' brenda - klyuchevoe ponyatie "brend-menedzhmenta" [Brand identity is a key concept of "brand management"]. Brend-menedzhment. 3. pp. 130-144.

3. Novikov, V. (2012) Otdayte emu ego identichnost' [Return him his identity]. [Online] Available from: http://svpressa.ru/society/article/62627/. (Accessed: 2nd July 2016).

4. Penzin, E. (2012) I ob identichnosti [And on the identity]. [Online] Available from: http://simk.ru/2012/12/20/i-ob-identichnosti/. (Accessed: 2nd July 2016).

5. Locke, J. (1985) Sochineniya: $v 3$ t. [Works. In 3 vols]. Translated from English. Vol. 1. Moscow: Mysl'. pp. 78-582.

6. Simmel, G. (2006) Group Expansion and the Development of Individuality. In: Calhoun, G. et al. (eds) Classical Sociological Theory. Blackwell Publishing. pp. 251-293.

7. Mead, G. (1934) Mind, Self and Society. Chicago: University of Chicago Press. pp. 152-164.

8. Coulee, C. (1994) Sotsial'naya samost' [Social Self]. In: Dobrenkov, V.I. (ed.) Amerikanskaya sotsiologicheskaya mysl' [American sociological thought]. Moscow: Moscow State University. pp. 320-321.

9. Goffman, E. (1963) Stigma: Notes on the Management of Spoiled Identity. New York: Prentice-Hall.

10. Berger, P. (1996) Priglashenie v sotsiologiyu: gumanisticheskaya perspektiva [Invitation to Sociology: Humanistic Perspective]. Moscow: Aspekt Press.

11. Freud, Z. (1980) Massovaya psikhologiya i analiz chelovecheskogo "Ya" [Mass psychology and analysis of the human "I"]. In: Galperin, P.Ya. \& Zhdan, A.N. (eds) Ya i Ono: Khrestomatiya po 
istorii psikhologii [I and It: Anthology on the History of Psychology]. Moscow: Moscow State University. pp. 170-192.

12. Jaspers, K. (1997) Obshchaya psikhopatologiya [General Psychopathology]. Translated from German by L.O. Akopyan. Moscow: Praktika.

13. Erickson, E. (2006) Identichnost': yunost' i krizis [Identity: Youth and crisis]. Translated from German by A. Andreeva, A. Prikhozhan, V. Rivosh, N. Tolstykh. Moscow: Flinta.

14. Ricoeur, P. (1995) Germenevtika. Etika. Politika: Moskovskie lektsii i interv'yu [Hermeneutics. Ethics. Politics: Moscow lectures and interviews]. Transkated from French. Moscow: KAMI. pp. 19-37.

15. Zakovorotnaya, M.V. (1999) Identichnost' cheloveka: Sotsial'no-filosofskie aspekty [Human Identity. Socio-philosophical aspects]. Rostov on Don: SKNTs VSh. 